This is the authors' version of a work that was accepted for publication in Economics and Human Biology. Changes resulting from the publishing process, such as peer review, editing, corrections structural formatting and other quality control mechanisms may not be reflected in this document. Changes may have been made to this work since it was submitted for publication. A definitive version was subsequently published in Economics and Human Biology, Vol 11, Issue 4, December 2013. DOI: 10.1016/j.ehb.2013.04.001

Published details:

Dercon, Stefan and Alan Sanchez (2013) 'Height in mid childhood and psychosocial competencies in late childhood: Evidence from four developing countries', Economics and Human Biology 11 (4): 426-432. Available online at: http://www.sciencedirect.com/science/article/pii/S1570677X13000361

The article is reproduced in accordance with the self-archiving policies of Elsevier. 


\title{
Height in mid childhood and psychosocial competencies in late childhood: evidence from four developing countries $^{\text {厺 }}$
}

\author{
Stefan Dercon ${ }^{\mathrm{a}}$, Alan Sánchez ${ }^{\mathrm{a}, \mathrm{b}}$ \\ ${ }^{a}$ Department of International Development, University of Oxford, OX1 3 TB. \\ ${ }^{b}$ Economic Research Division, Banco Central de Reserva del Peru, Jr. Antonio Miró \\ Quesada 441-445, Lima-1, Peru.
}

\begin{abstract}
We use longitudinal data from children growing up in four developing countries (Peru, India, Vietnam, Ethiopia) to study the relationship between height at the age of 7 to 8 and a set of psychosocial competencies measured at the age of 11 to 12 that are known to be correlated with earnings during adulthood: self-efficacy, self-esteem and aspirations. Results show that a one standard deviation increase in height-for-age tends to increase self-efficacy, self-esteem and aspirations by $10.4 \%, 6.4 \%$ and $5.1 \%$, respectively. We argue that these findings are likely to be informing of an underlying relationship between undernutrition and the formation of non-cognitive skills.
\end{abstract}

Keywords:

Height, Undernutrition, Psychosocial competencies, Non-cognitive skills, Peru, India, Ethiopia, Vietnam

\footnotetext{
"We are grateful for the eight referees providing extensive comments during refereeing for this journal, and helpful advice from the editor, John Komlos. We thank John Hoddinott, Albert Park, Francis Teal, Patrice Engle, Inka Barnett and participants at seminars in Oxford, Edinburgh, Ottawa and Lima for providing comments on an earlier version of this paper. All errors and inaccuracies are our responsability. The data used are from the Young Lives project. Young Lives is core-funded by UK aid from the Department for International Development (DFID) and co-funded from 2010 to 2014 by the Netherlands Ministry of Foreign Affairs. www.younglives.org.uk.

Email address: asanchez@grade.org.pe (Alan Sánchez)
} 


\section{Introduction}

Empirical evidence supports the idea that there are returns to psychosocial competencies in the labour market: they offer better job opportunities and incomes. First, aspects such as attitude, communication skills, motivation and "personality" are high on the list of the characteristics sought by employers (Bowles et al., 2001). Second, contemporaneous, self-reported, measures of self-esteem, self-efficacy and future-orientedness are found to explain a substantial portion of the variation across earnings of otherwise similar individuals (Bowles et al., 2001; Cunha et al., 2006). Third, measures of psychosocial competencies observed during the childhood period -built using components from a behavioural problem index (antisocial behaviour, anxiety, depression and hyperactivity tests) - are found to predict education and labour market outcomes (Heckman et al., 2006).

The importance of psychosocial competencies has long been recognized (Mecca et al., 1989). However, only recently the economics field has started to put attention to the determinants of this type of skills. Cunha and Heckman (2008) find evidence to support the notion that non-cognitive skills ${ }^{1}$ are shaped during the early stages of the life cycle and influenced by parental investments in the same way that cognitive skills are, and that complementarities arise across skills (see also Doyle et al. (2009)). The skills formation model has since been tested in other countries (Coneus et al., 2012; Helmers and Patnam, 2011), with researchers finding similar albeit not fully consistent evidence. Coneus et al. (2012) observe that the parameters of the skills formation model might vary according to risk factors at birth, such as low birth-weight and low socioeconomic status.

This paper aims to contribute to the literature by analysing the relationship between height in mid childhood and psychosocial competencies in late childhood in the context of developing countries. Such relationship can be motivated by findings from the medical literature (see Grantham-McGregor et al. (1999)). Meeks et al. (1999) find that by age 12 to 24 months, stunted children report more apathy, less willingness to explore, are less happy and more fussy than non-stunted children. Follow-up studies at 11 to 12 and 17 to 18 years also show differences in the behavior of early stunted and non-stunted children (Chang et al., 2002; Walker et al., 2007). Given that

\footnotetext{
${ }^{1}$ Non-cognitive skills is a generic term used to encompass a large range of abilities, including psychosocial competencies.
} 
early stunting is informative of the nutritional history of a child this is suggestive of a likely relationship between undernutrition and the formation of psychosocial competencies. Results from these studies are particularly prone to omitted variable problems. ${ }^{2}$ However, they adequately motivate why it is of interest to test this relationship in a robust way, given the high prevalence of stunting in developing countries (Grantham-McGregor et al., 2007).

In this study we test the relationship between height-for-age at the age of 7 to 8 years $^{3}$ and survey-based indicators of self-esteem, self-efficacy and (educational) aspirations observed at the age of 11 to 12 years. We test this relationship using data from 3,300 children growing up in four developing countries: Peru, India, Vietnam, Ethiopia. Whilst an incomplete set of psychosocial competencies, the available indicators fit well within the literature since they have been found to be correlated with earnings during adulthood ${ }^{4}$ and to reflect important non-cognitive dimensions of adolescent development (Stajkovic and Luthans, 1998; Trzesniewski et al., 2003; Goldsmith et al., 1997). The same literature highlights that the selected non-cognitive dimensions are thought to be shaped early in life, to be heavily influenced by experiences and the environment and to become more stable as adolescence is reached.

The estimation method used is ordinary least squares. For each of the four country samples and for the pooled sample we present correlations with different sets of co-variates to test the robustness of the relationship. In the last section of the paper we provide an interpretation of the results linking our findings to the literature on undernutrition and the formation of skills.

\footnotetext{
${ }^{2}$ Covariates available were (as labeled by the authors): childs age and sex, hunger, housing, mother's PPVT, occupation, father present in home, victim of crime, witnessed violence. Covariates were offered stepwise. Estimations in Walker et al. (2007) included 2 to 3 controls

${ }^{3}$ Height-for-age is physical height re-expressed in terms of the distance between observed height and a reference height for age and sex.

${ }^{4}$ Bowles et al. (2001) report the beta coefficients obtained from different studies linking self-esteem and self-efficacy to log-earnings. Coefficients fluctuate between 0.07 and 0.14 in the case of self-esteem, and between -0.06 and -0.15 in the case of self-efficacy (in this case, a higher score implies a lower self-efficacy).
} 


\section{Data characteristics}

\subsection{The sample}

Data are from the Young Lives Project, ${ }^{5}$ a study tracking the lives of eight cohorts of children in four countries: Ethiopia, India (Andhra Pradesh), Peru and Vietnam. There are two age cohorts in each country. In this paper we concentrate on the Older Cohort, which consists of approximately 1,000 children from each country (700 in Peru) born in 1994-5. To select the children, a multi-stage sampling procedure was used. Firstly, twenty clusters were selected from each country; at random in Peru and based on a number of predetermined criteria in the other three countries. ${ }^{6}$ Secondly, within each cluster, a village/town (or a group of villages/towns) and a group of eligible households within each village/town was chosen at random, respectively. ${ }^{7}$ For simplicity, we will treat the terms cluster and community as equals.

While the samples (with the exception of Peru) were not selected to be nationally representative, their wide geographical and ethnic coverage make them informative of the living conditions faced by the population in each of the studied countries. Approximately 50 households were selected in each village/town or group of villages/towns and in-depth information was collected for the eligible child (aged 7 to 8 at the time of the baseline survey) within each household. The sampled children and their caregivers were interviewed twice: in 2002, when they were 7 to 8 years; and, in 2006-7, when they were 11 to 12 years. ${ }^{8}$ The survey provides information on a variety of aspects related to child development, including child and maternal indicators of perceptions, attitudes and aspirations, child cognitive test scores, child and maternal anthropometric measures, as well as wide array of information on child, family and other contextual characteristics. Attrition in the samples is exceptionally low: only $1.4 \%$ of the children were lost or dropped out in the samples between the two rounds on average, with the Peru sample facing attrition of $3.5 \%$ and the Vietnam sample only $0.5 \%$.

\footnotetext{
${ }^{5}$ See http://www.younglives.org.uk/

${ }^{6}$ Clusters are small geographical units. The exact definition depends on the country (districts in Peru, communes in Vietnam, mandals in Andhra Pradesh and weredas in Ethiopia).

${ }^{7}$ The household eligibility criterion consisted in having a child aged 7 to 8 year old at the time of the first survey round.

${ }^{8}$ They have since been interviewed at the age of 15 .
} 


\subsection{Measurements variables}

\subsubsection{Height-for-age}

The World Health Organization (WHO) estimates growth standards for children aged less than 5 years old, which are used to assess chronic malnutrition. Similarly, WHO estimates growth references for school-aged children and adolescents. To use these growth curves, height is transformed into height-for-age z-scores that measure the distance between a given child and the norm child for the corresponding age and sex. A child with a height-forage z-score below -2 (that is 2 standard deviations below the median, healthy child) is classified as stunted. We use height-for-age z-scores at the age of 7 to 8 . The percentage of children classified as stunted using this indicator fluctuates between 26 and 31 per cent in the country samples. As expected, the samples with a higher proportion of children living in poverty (Ethiopia and India) report the highest levels of stunting (table 1). For the estimations, we chose to use the height-for-age variable in its continuous form (as opposed to the binary variable based on the WHO cut-off points for stunted) to fully exploit the information conveyed by this variable.

Table 1: Young Lives sample poverty levels and nutritional rates by country

\begin{tabular}{lcccc} 
& Peru & India & Vietnam & Ethiopia \\
\cline { 2 - 5 } & $(1)$ & $(2)$ & $(3)$ & $(4)$ \\
\hline $\begin{array}{l}\text { Wealth index } \\
\begin{array}{l}\text { Percentage of stunted children } \\
\text { at 7-8 years }\end{array}\end{array}$ & 0.51 & 0.34 & 0.44 & 0.17 \\
\hline \hline
\end{tabular}

Notes: (a) The wealth index comprises information on three dimensions: housing quality (characteristics of roof, wall, floor and number of rooms per person), holding of consumer durables (radio, TV, fridge, bike, car, among others) and access to services (electricity, drinking water, flush toilet and type of fuel used for cooking). The index ranges from 0 to 1 where 0 (1) corresponds to a household with the worst (best) possible outcomes in the three selected dimensions. (b) A child is classified as stunted if his/her height-for-age $\mathrm{z}$-score is below -2 .

\subsubsection{Measurements of psychosocial competencies}

Using survey data, we construct a set of indicators that intend to approximate children's competencies in the following dimensions: (a) self-efficacy; (b) self-esteem; and, (c) aspirations. The concepts of self-esteem and selfefficacy have been extensively studied in the field of psychology, particularly the former. Self-esteem is related to a person's overall evaluation of her own worth. In turn, self-efficacy is related to a person's sense of agency or 
mastery over his life. Individuals hold beliefs about whether outcomes are due to their own efforts or the result of luck, fate, or the intervention of others. Individuals who believe that outcomes are due to their own efforts have a high "internal" locus of control (Maddux, 1991), i.e., a high sense of agency. To measure these two psychosocial traits, we estimated indicators based on respondents' degree of agreement or disagreement with a number of statements. The degree of agreement is measured on a 4-point Likert scale that ranges from strong agreement to strong disagreement. In turn, answers to these statements are used to construct individual average scores on selfefficacy and self-esteem. Statements used for the construction of each index were drawn from the educational psychology literature, although they were adapted and extensively tested during piloting for use with children across different cultures.

For self-esteem, the statements explored in the Young Lives survey focused largely on positive and negative dimensions of pride and shame. They are effectively an adapted version of the Rosenberg Self-Esteem Scale (Rosenberg, 1965), more focused on specific dimensions of children's living circumstances (housing, clothing, work, school). The self-esteem index is the average score of nine items. ${ }^{9}$ Similarly, the self-efficacy index is the average score of five items. ${ }^{10}$ In both cases, negative statements are recoded in inverse order. Histograms of both indicators are reported in Figure A.1 in the appendix. $^{11}$

One concept often assessed in the context of psychological tests is internal consistency (sometimes called reliability or homogeneity). The notion is that, in a homogenous psychological test, items measure the same thing (Cronbach, 1951). The Cronbach's alpha, a statistic based on the correlation of different items of the same test, is deemed as a test of internal consistency in the sense

\footnotetext{
${ }^{9}$ The items are: 'I feel proud to show my friends or other visitors where I live', 'I am ashamed of my clothes', 'I feel proud of the job done by the head of my household', 'I am often embarrassed because I do not have the right books, pencils or other equipment for school', 'I am proud of my achievements at school', 'I am embarrassed by/ashamed of the work I have to do', 'I am ashamed of my shoes', 'I am worried that I don't have the correct uniform' and 'The job I do makes me feel proud'.

${ }^{10}$ 'If I try hard I can improve my situation in life', 'Other people in my family make all the decisions about how I spend my time', 'I like to make plans for my future studies and work', 'I have no choice about the work I do - I must do this sort of work' and 'If I study hard at school I will be rewarded by a better job in future'.

${ }^{11}$ Both indicators are standardized to have mean 0 and variance 1 within each country.
} 
that a relatively high alpha (above 0.70) supports the notion that there is a common factor behind answers to different items. In our analysis we obtain values of 0.89 and 0.95 for the self-efficacy and self-esteem indicators in the pooled sample, respectively.

Another competence that interests us is related to a child's aspirations. Quaglia and Cobb (1996) define aspirations as the 'ability to identify and set goals for the future, while being inspired in the present to work toward those goals'. In the child development literature, the role of aspirations and its link with educational outcomes has long been emphasised (Bandura et al., 2001; Cohen et al., 2009). A recent study in a developing country tests the relevance of aspirations for girls' achievement, including in education, and how they can be boosted, using a natural experiment (Beaman et al., 2012).

Because of the age-period in which the sampled children are observed we focus on educational aspirations as the outcome of interest, measured by asking the child how far she hopes to get in educational terms. ${ }^{12}$ The answer is expressed in equivalent years of education, asking for the highest grade of education that the child hopes to complete. Table 2 gives the mean educational aspirations for each country with the standard deviation in brackets. A histogram of this variable is reported in Figure A.1 for the pooled sample. ${ }^{13}$

Table 2: School aspirations: descriptive statistics

\begin{tabular}{lccccc} 
& Peru & India & Vietnam & Ethiopia & All \\
\cline { 2 - 6 } & $(1)$ & $(2)$ & $(3)$ & $(4)$ & $(5)$ \\
\hline Mean & 15.14 & 15.06 & 15.64 & 15.42 & 15.33 \\
S.D. & $(1.83)$ & $(3.00)$ & $(2.48)$ & $(2.73)$ & $(2.60)$ \\
& & & & & \\
$\mathrm{n}$ & 640 & 859 & 936 & 855 & 3290 \\
\hline \hline
\end{tabular}

Notes: school aspirations are expressed in terms of the number of years of schooling the child hopes to get.

\footnotetext{
${ }^{12}$ The exact question was: 'Imagine you had no constraints and could stay at school as long as you liked. What level of formal education would you like to complete?'

${ }^{13}$ Variables are standardized to have mean 0 and variance 1 within each country.
} 


\section{Main Results}

Table A.3 (in the appendix) reports pair-wise correlations between heightfor-age and the three selected psychosocial indicators. Results are reported by country and for the pooled sample. In the pooled sample, the correlation is positive and statistically significant for all the psychosocial dimensions included. Because variables on both sides of the regression are standardized with mean 0 and variance 1 , the marginal effects can be interpreted in terms of the proportion of the standard deviation of the outcomes explained by height-for-age. An increase of one standard deviation in height-for-age tends to increase school aspirations, self-efficacy and self-esteem by $16.4 \%, 7.0 \%$ and $10.1 \%$ of the standard deviation of school aspirations, self-efficacy and self-esteem scores, respectively. On a country-by-country basis, we find that height-for-age is positively correlated with school aspirations in all countries; and with self-esteem and self-efficacy in Peru, India and Vietnam. In every case, the sign of the coefficient is positive, as expected.

To assess this relationship in a robust way, we regress each of the selected measurements on lagged height-for-age by ordinary least squares including co-variates at the child and household level and taking into account characteristics of the community. Specifically, for child $i$ born in cluster ${ }^{14} j$ we estimate the following linear equation,

$$
S_{i j, t}^{P}=\beta H_{i j, t-1}+X_{i j, t} \Gamma+\alpha_{j}+\mu_{i j, t}
$$

where $S_{i j, t}^{P}$ stands for psychosocial competencies measured at 11 to 12 years (aspirations, self-efficacy and self-esteem) of child $i$ from cluster $j$ measured in period $t ; H_{i j, t-1}$ stands for height-for-age at 7 to 8 years; $\alpha_{j}$ represents community characteristics that are constant over time; $X_{i j, t}$ is a vector of controls; $\mu_{i j, t}$ is the error term. The elements incorporated in $X_{i j, t}$ are: (a) child's gender, age, birth order, disability status and mother tongue; (b) caregiver's relationship to the child, age, years of education, ethnicity (caste in India), marital status and disability status; and, (c) household size, gender of the head of the household, housing quality (wall, floor and roof building materials and numbers of rooms per person) and access to services (drinking water, electricity, toilet facilities and type of cooking fuel used). Exception made of child's age and disability status, all the variables were measured when

\footnotetext{
${ }^{14}$ Community and cluster are used as synonymous.
} 
the child aged 7 to 8 years. We consider child and family characteristics as predetermined. For simplicity we assume no fertility choices.

The height-for-age coefficients obtained from estimating this specification (baseline specification) are reported in Table A.4, PANEL A (see appendix) for the pooled sample and for each of the studied countries. Focusing on the pooled sample, we find that height-for-age remains associated with school aspirations, self-efficacy and self-esteem. An increase of one standard deviation in height-for-age, keeping everything else constant, tends to increase school aspirations, self-efficacy and self-esteem by $10.4 \%, 6.4 \%$ and $5.1 \%$ of the standard deviation of school aspirations, self-efficacy and self-esteem scores, respectively. F-tests are reported to assess the null hypothesis that the nutrition coefficient is the same across countries. The hypothesis is only rejected in one case (school aspirations) at the 10\% confidence level and as more controls are added -see subsection 4- the hypothesis is not rejected in any case. This suggest that there is a mechanism linking height-for-age to psychosocial competencies that is common across countries.

\section{Robustness checks}

Omitted variable bias is likely to be a problem in this specification since there are determinants of parental investments in psychosocial development that are unobserved by the econometrician and that might be correlated with height-for-age. First, monetary poverty, a likely correlate of height-for-age due to the relationship between early height and nutrient intake, can also play a role in shaping psychosocial competencies (Dercon and Krishnan, 2009). This aspect is controlled for, albeit imperfectly, in the baseline specification. Second, height-for-age could be correlated with concurrent, short-term nutritional problems (low or, indeed, high weight relative to age). ${ }^{15}$ Third, the unobserved household psychosocial environment could bias the result if it is correlated with the household health environment.

To deal with these possibilities we present results for an extended specification. First, we include contemporaneous household consumption expendi-

\footnotetext{
${ }^{15}$ We are not aware of a relationship between concurrent nutritional deficits and psychosocial outcomes. However, there is evidence in the opposite direction, linking obesity to the development of social skills (Cawley and Spiess, 2008). In either case, we would like to disentangle concurrent nutritional problems from the nutritional history of a child. The latter is of interest to us.
} 
ture (in per capita terms, expressed in logs) and also add controls for household vulnerability to a variety of economic shocks (natural disasters, changes in the availability of food, livestock died, failed crop, stolen livestock, stolen crop, job loss, loss of family income, severe illness or injury of one member of the family $\left.{ }^{16}\right)$. Second, we add contemporaneous child body mass index as a control in the estimation. Third, to deal with the potential influence of household psychosocial environment we resort to proxy variables. We add caregiver psychosocial indicators (the caregiver is, typically, the mother) to proxy for the household environment in which the child develops her psychosocial competencies. These indicators are analogous versions of those defined for the child, constructed on the basis of statements reflecting the caregiver's competencies in the areas of self-esteem and self-efficacy. In the case of educational aspirations, it measures the number of years of education the caregiver hopes her child to achieve.

A summary of the results obtained after adding these additional controls (extended specification) is presented in Table A.4, PANEL B. Also, Table A.5 reports the marginal effects of a selected set of controls for the pooled sample estimations, with all the variables standardized to have mean and variance equal to 0 and 1 (respectively). The resulting coefficients are of a smaller magnitude, as expected. Comparing the baseline specification to the extended one, the point estimates of the nutrition effects in the pooled sample reduce from 0.104 to 0.078 for school aspirations, from 0.064 to 0.058 for self-efficacy and from 0.051 to 0.034 for self-esteem. In all cases, results remain statistically significant at standard levels.

Two other results must be highlighted. First, household consumption expenditure is found to be strongly correlated with psychosocial outcomes (Table A.5). Second, maternal psychosocial competencies turn out to be the most important correlate of the child's competencies. These results are consistent with Dercon and Krishnan (2009). The standardized coefficients for each of the selected indicators (caregiver's aspirations for the child, selfesteem and self-efficacy respectively) on the analogous child indicators are $0.385,0.272$ and 0.107 , respectively. Caution is needed, however, to interpret the result. Since maternal aspirations are measured contemporaneously to the child psychosocial measures, there could be a problem of reverse feedback (a mother's aspirations for her child could be influenced by the child's own

\footnotetext{
${ }^{16}$ Reported when the child was aged 7 to 8 years.
} 
aspirations) or a common unobserved determinant. Therefore, one should not give a causal interpretation to this result.

\section{Interpreting the results}

What could explain the relationship found between height-for-age at 7 to 8 years and psychosocial competencies at 11 to 12 ? Height-for-age z-scores at the age of 7 to 8 is associated to early nutrition. ${ }^{17}$ Thus, it is likely that results could be informing of an underlying relationship between undernutrition and the formation of non-cognitive skills. The role of early undernutrition in skills formation is of relevance in the context of developing countries, where food security, lack of access to clean water and basic health services remain an important challenge. While the impact of undernutrition on cognitive skills formation has received considerable attention in the economic literature and in other fields, to our knowledge the possible implications of undernutrition during childhood on the acquisition of non-cognitive skills has received little attention within the human capital formation literature in economics. It has been hypothesized, however, in other fields (Meeks et al., 1999; Chang et al., 2002; Walker et al., 2007).

One possible criticism to this line of reasoning is that our results could be merely reflecting the impact of relative height on psychosocial outcomes instead of the long-term implications of investments in early nutrition. This line of interpretation takes the role of peers in determining a child's noncognitive skills seriously. For instance, if relatively short children are more likely to be bullied at school, this could explain why stunted children (if they are indeed a minority) have poorer psychosocial outcomes. But, were this

\footnotetext{
${ }^{17}$ Although conceptually an earlier measure of height-for-age -i.e., between 3 and 5 years- would be a better measurement variable to capture early nutritional investments -e.g., due to the possibility of nutritional catch-up-, it is important to note the following. First, by the standards of the related literature our indicator has been measured early enough to be informative of nutritional investments (Habicht et al., 1974). Second, our indicator was observed before puberty, a stage when genetic disparities in physical height across ethnic groups become more pronounced. Third, there is little evidence of faltering or appreciable nutritional catch-up before adolescence (Martorell, 1999). Fourth, to statistically test whether physical height at the age of 7-8 conveys information from the first few years of life, we used data from other cohort tracked by the Young Lives project, and find that the correlation between height at age 6-24 months and height at 7-8 years of age is 0.69 . Overall, we think this gives sufficient ground to use height-for-age 7-8 as an indicator of early nutritional investments.
} 
to be the case, a similar relationship could be found in countries with low prevalence of undernutrition. While it is not possible to entirely rule out this possibility with the available information, we do the following. Since differences in height-for-age are assumed to convey information about nutritional differences mostly in the lower tail of its distribution, we split the pooled sample in two, separating those with a height-for-age below -1 from the rest. Results are reported in Table A.4 for both the baseline and the extended specification. We find what one would expect under this line of reasoning. The height-for-age coefficients are larger for the sub-sample of children with low height-for-age and only in this case there is statistical significance. In other words, being taller is good only insofar as this makes a child moving from stunting to non-stunting levels. As an additional check, we re-estimate the model for sub-samples where only children living in communities where stunted children are not a minority are included. Doing this reduces the likelihood that stunted children could be treated differently because of their relative height. The average community in the sample includes 50 children and many of these children are, in practice, school peers. For our purpose, we focus on communities where more than $25 \%$ of children are stunted (results with a $10 \%$ threshold are also reported). Estimation results are reported in Table A.6 (in the appendix). Results remain similar in these alternative specifications in terms of the point estimates.

\subsection{The role of academic performance}

If results are interpreted as informative of the relationship between undernutrition and the formation of psychosocial competencies, it is important to discuss whether part of the relationship observed can be explained by the effect that nutrition has on schooling dimensions that in turn can act as inputs of psychosocial outcomes. This is likely to be the case. Compared to well-nourished children, malnourished children are more likely to spend less time in school due to delayed enrolment (Glewwe and Jacoby, 1995) and are more likely to have a low academic performance (Alderman et al., 2006; Glewwe et al., 2001; Cinnirella et al., 2011; Spears , 2012). In turn, delayed school enrolment and low academic performance can affect aspirations and self-esteem.

Whether or not this is the case, it is problematic to assess empirically. First, adding academic performance and delayed enrolment into the estimation amplifies the endogeneity problem. Second, we would like to observe academic performance some time between $t-1$ ( 7 to 8 years) and $t$ (11 to 
12) to avoid the problem of reverse feedback. Unfortunately, we only observe academic performance (reading and writing skills) at ages 7 to 8 . Nevertheless, we still find it useful to include them as controls. Our justification is that height-for-age at ages 7 to 8 conveys information mainly about nutritional investments that take place during the early childhood period, whereas the acquisition of writing and reading skills as well as the timing of school enrolment reflect investments that happen at a later stage. Although the assumption is strong, under this scenario the nutrition coefficient obtained after introducing these variables into the estimation can be considered informative.

To proceed, we create binary variables that take the value of 0 if the child has a low (undesirable) level of a certain input (low reading skills, low writing skills or school enrolment off-age) and 1 otherwise. A child is considered to have high reading skills if she is able to read sentences (as opposed to only words or letters, or not being able to read at all) and high writing skills if able to write without difficulty and without errors. ${ }^{18}$ While these are crude measures of schooling achievement, they are relevant in the context of lowincome countries, where a significant proportion of children are unable to read and write properly. The proportion of children with low reading and writing skills in the pooled sample are $41 \%$ and $49 \%$, respectively. Similarly, $25 \%$ of the sampled children are off-age (i.e., they were enroled in school after the norm-age).

Results are reported in Table A.7. ${ }^{19}$ Both reading and writing skills at the age of 7 to 8 years are found to be predictors of the selected psychosocial indicators. The nutrition coefficient obtained in the extended specifications is smaller in both cases: moving from 0.083 to 0.071 in the case of school aspirations; from 0.054 to 0.047 in the case of self-efficacy; and, from 0.031 to 0.021 in the case of self-esteem. With the caveats mentioned above, the change in the point estimates does not seem to be large enough to claim that the relationship found is mediated by academic performance or by delayed enrolment.

\footnotetext{
${ }^{18}$ In each country, children were asked to read letters, words and sentences from a card and to write sentences under the supervision of the interviewer.

${ }^{19}$ Note that the sample is smaller than that used in the previous estimations. This is because of missing observations in the reading and writing tests ( 84 missing observations). Despite this, the same patterns found when using the original sample are also found in this new sample.
} 
We focused on these channels because they are discussed in the literature. However it is important to highlight that there could be other pathways through which the relationship found is mediated that can not be explored because of data constraints. In particular, it is possible that well-nourished children attract more skills-related investments within the household and at school.

\section{Conclusions}

Empirical evidence and common sense indicate that non-cognitive skills are rewarded in the labour market, in the same way that cognitive skills are. Although it is relatively well understood how cognitive skills are produced, until recently the analogous process for non-cognitive skills had been little explored in the economics field. We find evidence of a robust, positive, correlation between height-for-age measured during mid-childhood ( 7 to 8 years of age) and three indicators of psychosocial competencies observed during the last stage of childhood (age 11 to 12, just before adolescence begins). Although we are only equipped to show association, in our specification we control for a wide range of potential confounders.

To put these results in context, consider the case of a child that moves from the 10th to the 50th percentile of the height-for-age distribution and that is otherwise average. Using the previously estimated coefficients (extended specification) this movement tends to increase school aspirations, self-efficacy and self-esteem by $10.0 \%, 7.4 \%$ and $4.4 \%$ standard deviations, respectively. Comparatively, when simulating similar movements in the distribution of other factors, the only dimension that has a more important association with these indicators are the analogous maternal psychosocial competencies. Compared to height-for-age, a move from the lowest decile to the median value of access to services, household consumption expenditure per capita and maternal education is associated with increases of a smaller magnitude in almost all cases. ${ }^{20}$

We hypothesize that our results might be informing of an underlying relationship between undernutrition and the formation of psychosocial com-

\footnotetext{
${ }^{20}$ The marginal effect of moving from the 10th to the 50th percentile of the access to services index, household consumption expenditure per capita and maternal education (one at a time) is as follow: $2.4 \%, 1.9 \%$ and $3.4 \% ; 2.1 \%, 1.3 \%$ and $4.5 \%$; and, $8.3 \%, 1.3 \%$ and $7.9 \%$, respectively.
} 
petencies. This opens tasks for future research. It is important to establish whether the degree of malnutrition matters to explain psychosocial development and whether the nutrition effect is more relevant in certain stages of childhood. Also, more work is needed to assess the direct and indirect channels through which undernutrition can affect psychosocial development.

\section{References}

Alderman, H., Hoddinott, J.,Kinsey,B., 2006. Long term consequences of early childhood malnutrition. Oxford Economic Papers 58 (3), 450-474.

Almond, D., 2006. Is the 1918 influenza pandemic over? long-term effects of in utero influenza exposure in the post-1940 U.S. population. Journal of Political Economy 114 (4), 672-712.

Bandura, A., Barbaranelli, C., Caprara, G., Pastorelli, C., 2001. Self-efficacy beliefs as shapers of children's aspirations and career trajectories. Child Development 72 (1), 187-206.

Beaman, L., Duflo, E., Pande, R., Topalova, P., 2012. Female Leadership Raises Aspirations and Educational Attainment for Girls: A Policy Experiment in India. Science 335, 582-586.

Bowles, S., Gintis, H., Osborne, M., 2001. The determinants of earnings: a behavioral approach. Journal of Economic Literature 39 (4), 1137-1176.

Cawley, J., Spiess, C.K., 2008. Obesity and skill attainment in early childhood. Economics and Human Biology 6 (3), 388-397.

Cinnirella, F., Piopiunik, M., Winter, J., 2011. Why does height matter for educational attainment? evidence from German children. Economics and Human Biology, 9(4), 407-418.

Cohen, G., Garcia, J., Purdie-Vaughns, V., Apfel, N., Brzustoski, P., 2009. Recursive processes in self-affirmation: Intervening to close the minority achievement gap. Science, 324, 400-403.

Coneus, K., Laucht, M., Reu, K., 2012. The role of parental investments for cognitive and noncognitive skill formation - Evidence for the first 11 years of life. Economics and Human Biology, 10(2), 189-209. 
Cronbach, L.J., 1951. Coefficient alpha and the internal structure of tests. Psychometrika 16 (3), 297-334.

Cunha, F., Heckman, J.J., Lochner, L., 2006. Interpreting the evidence on life cycle skill formation. Handbook of the Economics of Education, Chapter $12,697-812$.

Cunha, F., Heckman, J.J., 2007. The technology of skill formation. American Economic Review 97 (2), 31-47.

Cunha, F., Heckman, J.J., 2008. Formulating, identifying and estimating the technology of cognitive and noncognitive skill formation. Journal of Human Resources 43 (4), 738-782.

Cunha, F., Heckman, J.J., Schennach, S.S., 2010. Estimating the technology of cognitive and noncognitive skill formation. Econometrica 78 (3), 883931.

Chang, S.M., Walker, S.P., Grantham-McGregor, S., Powell, C.A., 2002. Early childhood stunting and later behaviour and school achievement. Journal of Child Psychology and Psychiatry and Allied Disciplines 43 (6), 775-783.

Dercon, S., Krishnan, P., 2009. Poverty and the psychosocial competencies of children: evidence from the Young Lives sample in four developing countries. Children, Youth and Environments 19 (2), 138-163.

Doyle, O., Harmon, C., Heckman, J., Tremblay, R., 2009. Investing in early human development: timing and economic efficiency. Economics and $\mathrm{Hu}-$ man Biology, 7(1), 1-6.

Duckworth, A., Seligman, E., 2005. Self-Discipline Outdoes IQ in Predicting Academic Performance, Psychological Science 16 (12), 939-944.

Glewwe, P., Jacoby, H.G., 1995. An economic analysis of delayed primary school enrollment in a low income country: the role of early childhood nutrition. The Review of Economics and Statistics 77 (1), 156-169.

Glewwe, P., Jacoby, H.G., King, E., 2001. Early childhood nutrition and academic achievement: a longitudinal analysis. Journal of Public Economics 81 (3), 345-368. 
Goldsmith, A.H., Veum, J.R., Darity, W.J., 1997. The impact of psychological and human capital on wages. Economic Inquiry 35 (4), 815-829.

Grantham-McGregor, S., Cheung, Y., Cueto, S., Glewwe, P., Richter, L., Strupp, Barbara., 2007. Developmental potential in the first 5 years for children in developing countries. The Lancet 369 (9555), 60-70.

Grantham-McGregor, S.M., Fernald, L., Sethuraman, K., 1999. Effects of health and nutrition on cognitive and behavioural development in children in the first three years of life. Food and Nutrition Bulletin 20 (1), 53-75.

Grantham-McGregor, S.M., Walker, S.P., Chang, S.M., Powell, C.A., 1997. Effects of early childhood supplementation with and without stimulation on later development in stunted Jamaican children. American Journal of Clinical Nutrition 66 (2), 247-253.

Grantham-McGregor, S.M., Powell, C.A., Walker, S.P., Himes, J.H., 1991. Nutritional supplementation, psychosocial stimulation, and mental development of stunted children: the Jamaican Study. The Lancet 338 (8758), $1-5$.

Habicht, J., Yarbrough, C., Martorell, R., Malina, R., Klein, R, 1974. Height and weight standards for preschool children. How relevant are ethnic differences in growth potential? The Lancet 1, 611615 .

Haas, J., Campirano, F., 2006. Interpopulation variation in height among children 7 to 18 years of age. Food and Nutrition Bulletin 17 (4), S212S223.

Heckman, J.J., Stixrud, J., Urzua, S., 2006. The effects of cognitive and noncognitive abilities on labor market outcomes and social behavior. Journal of Labor Economics 24 (3), 411-482.

Helmers, C., Patnam, M., 2011. The formation and evolution of childhood skill acquisition: Evidence from India. Journal of Development Economics 95 (2), 252-266.

Linnemayr, S., Alderman, H., Ka, A., 2008. Determinants of malnutrition in Senegal: individual, household, community variables, and their interaction. Economics and Human Biology, 6(2), 252-263. 
Maddux, J., 1991. Self-efficacy. Handbook of social and clinical psychology, 57-78.

Maluccio, J., Hoddinott, J., Behrman, J.R., Martorell, R., Quisumbing, A.R., Stein, A.D., 2009. The impact of improving nutrition during early childhood on education among guatemalan adults. Economic Journal 119 (537), 734-763.

Martorell, R., 1999. The nature of child malnutrition and its long-term implications. Food and Nutrition Bulletin 20, 288-292.

Mecca, A., Smelser, N., Vasconcellos, J., 1989. The social importance of self-esteem. University of California Press in Berkeley.

Meeks, J., Grantham-McGregor, S., Himes, J., Chang, S., 1999. Behaviour and Development of Stunted and Nonstunted Jamaican Children. Journal of Child Psychology and Psychiatry 40 (5), 819-827.

Pelletier, D., 2006. Theoretical considerations related to cutoff points. Food and Nutrition Bulletin 17 (4), S224-S236.

Pollitt, E., Gorman, K.S., Engle, P.L., Martorell, R., Rivera, J., Wachs, T.D., Nevin S.S., 1993. Early supplementary feeding and cognition: effects over two decades. Monographs of the Society for Research in Child Development $58, \mathrm{i}-118$.

Quaglia, R., Cobb, C., 1996. Toward a theory of student aspirations. Journal of Research in Rural Education 12 (3), 127-132.

Rosenberg, M., 1965. Society and the adolescent self-image. Princeton, NJ. Princeton University Press.

Rosenzweig, M., Schultz, P., 1983. Estimating a Household Production Function: Heterogeneity, the Demand for Health Inputs, and Their Effects on Birth Weight. Journal of Political Economy, 91 (5), 723-746.

Spears, D., 2012. Height and cognitive achievement among Indian children. Economics and Human Biology, 10(2), 210-219.

Stajkovic, A., Luthans, F., 1998. Self-efficacy and work-related performance: a meta-analysis. Psychological Bulletin 124 (2), 240-261. 
Trzesniewski, K.H., Donnellan, M.B., Robins, R.W., 2003. Stability of selfesteem across the life span. J Pers Soc Psychol 84 (1), 205-220.

Walker, S., Chang, S., Powell, C., Simonoff, E., Grantham-McGregor, S., 2007. Early childhood stunting is associated with poor psychological functioning in late adolescence and effects are reduced by psychosocial stimulation. Journal of Nutrition 137, 2464-2469. 


\section{Appendix A. Supplementary figures and tables}

Figure A.1: Histograms
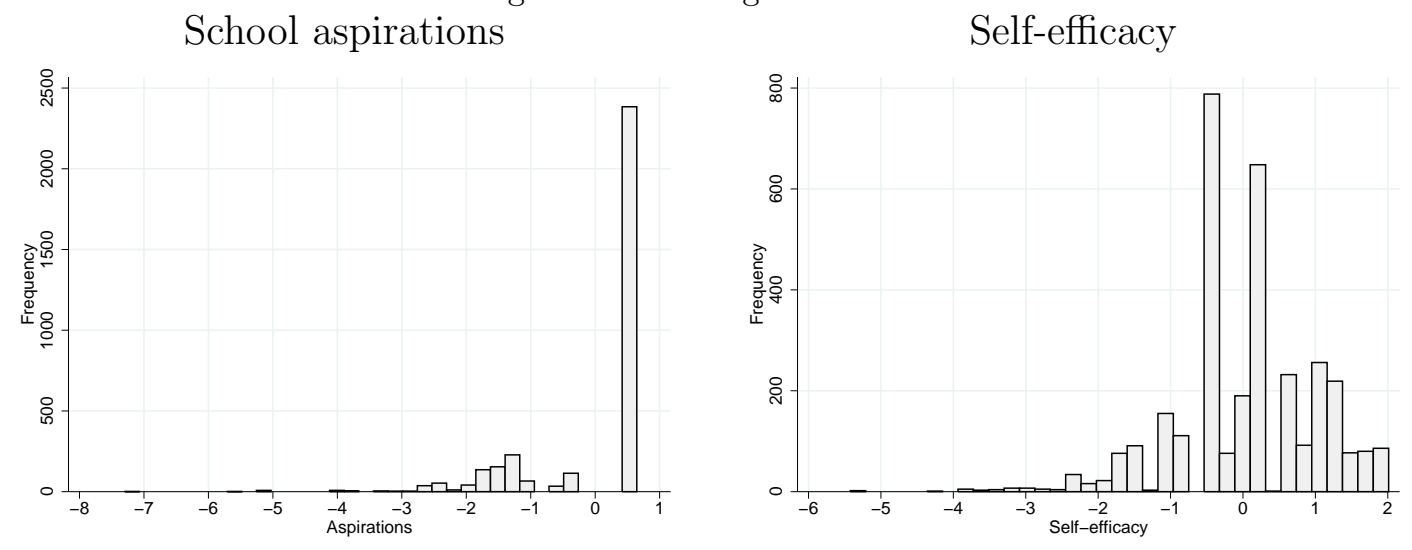

\section{Self-esteem}

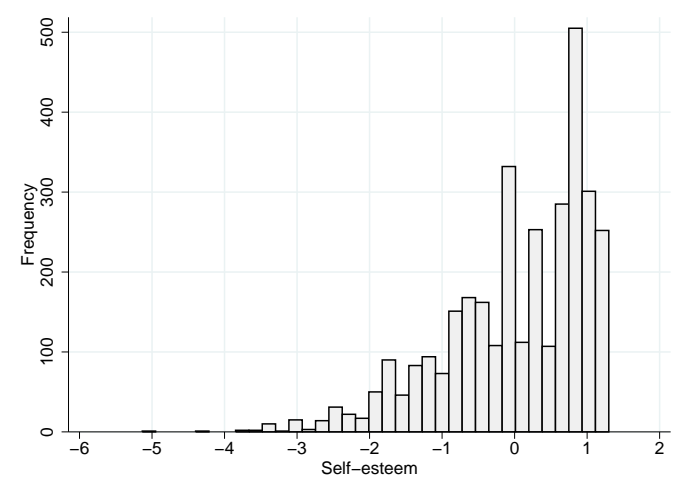

Pooled sample. All variables were standardized to have mean 0 variance 1 in each country. 
Table A.3: Simple pair-wise correlations: non-cognitive skills at age 11 to 12 and heightfor-age at age 7 to 8

\begin{tabular}{lcccc} 
& $\mathrm{n}$ & $\begin{array}{c}\text { School } \\
\text { aspirations }\end{array}$ & $\begin{array}{c}\text { Self } \\
\text { efficacy }\end{array}$ & $\begin{array}{c}\text { Self } \\
\text { esteem }\end{array}$ \\
\cline { 2 - 5 } & & $(1)$ & $(2)$ & $(3)$ \\
\hline Pooled sample & 3290 & 0.164 & 0.07 & 0.101 \\
& & $(0.028)^{* * *}$ & $(0.018)^{* * *}$ & $(0.026)^{* * *}$ \\
Country samples & 640 & 0.131 & 0.102 & 0.284 \\
Peru & & $(0.048)^{* * *}$ & $(0.053)^{*}$ & $(0.063)^{* * *}$ \\
& & 0.126 & 0.051 & 0.088 \\
India & 859 & $(0.037)^{* * *}$ & $(0.023)^{* *}$ & $(0.034)^{* *}$ \\
Vietnam & 936 & 0.232 & 0.083 & 0.096 \\
& & $(0.078)^{* * *}$ & $(0.024)^{* * *}$ & $(0.046)^{* *}$ \\
Ethiopia & 855 & 0.15 & 0.052 & -.020 \\
& & $(0.033)^{* * *}$ & $(0.046)$ & $(0.05)$ \\
F-test eq. of coeff. & & & & \\
\hline F & & 2.22 & 0.54 & 3.59 \\
p-value & & 0.092 & 0.674 & 0.017 \\
\hline
\end{tabular}

Variables are standardized to have mean 0 and variance 1. Each cell represents a different regression. Robust standard errors, clustered at the community level; *, ${ }^{* *},{ }^{* * *}$ denote significance at $10 \%, 5 \%$ and $1 \%$ levels. 
Table A.4: OLS results: non-cognitive skills at age 11 to 12 and height-for-age at age 7 to 8 (main results)

\begin{tabular}{|c|c|c|c|c|}
\hline & $\mathrm{n}$ & $\begin{array}{c}\begin{array}{c}\text { School } \\
\text { aspirations }\end{array} \\
(1)\end{array}$ & $\begin{array}{c}\begin{array}{c}\text { Self } \\
\text { efficacy }\end{array} \\
(2)\end{array}$ & $\begin{array}{c}\begin{array}{c}\text { Self } \\
\text { esteem }\end{array} \\
(3)\end{array}$ \\
\hline \multicolumn{5}{|c|}{ PANEL A: Baseline specification } \\
\hline Pooled sample & 3290 & $\begin{array}{c}0.104 \\
(0.018)^{* * *}\end{array}$ & $\begin{array}{c}0.064 \\
(0.018)^{* * *}\end{array}$ & $\begin{array}{c}0.051 \\
(0.018)^{* * *}\end{array}$ \\
\hline \multicolumn{5}{|l|}{ Country samples } \\
\hline Peru & 640 & $\begin{array}{l}0.079 \\
(0.047)^{*}\end{array}$ & $\begin{array}{l}0.037 \\
(0.065)\end{array}$ & $\begin{array}{c}0.103 \\
(0.039)^{* * *}\end{array}$ \\
\hline India & 859 & $\begin{array}{l}0.058 \\
(0.039)\end{array}$ & $\begin{array}{c}0.052 \\
(0.019)^{* * *}\end{array}$ & $\begin{array}{c}0.04 \\
(0.027)\end{array}$ \\
\hline Vietnam & 936 & $\begin{array}{c}0.109 \\
(0.029)^{* * *}\end{array}$ & $\begin{array}{c}0.109 \\
(0.034)^{* * *}\end{array}$ & $\begin{array}{c}0.066 \\
1(0.038)^{*}\end{array}$ \\
\hline Ethiopia & 855 & $\begin{array}{c}0.129 \\
(0.031)^{* * *}\end{array}$ & $\begin{array}{l}0.048 \\
(0.036)\end{array}$ & $\begin{array}{l}0.013 \\
(0.042)\end{array}$ \\
\hline \multicolumn{5}{|l|}{ Pooled sample } \\
\hline Height-for-age $<-1$ & 2176 & $\begin{array}{c}0.117 \\
(0.042)^{* * *}\end{array}$ & $\begin{array}{l}0.072 \\
(0.030)^{* *}\end{array}$ & $\begin{array}{c}0.082 \\
(0.032)^{* *}\end{array}$ \\
\hline Height-for-age $\geqq-1$ & 1114 & $\begin{array}{l}0.038 \\
(0.048)\end{array}$ & $\begin{array}{l}0.061 \\
(0.061)\end{array}$ & $\begin{array}{l}0.072 \\
(0.046)\end{array}$ \\
\hline \multicolumn{5}{|c|}{ PANEL B: Extended specification } \\
\hline Pooled sample & 3290 & $\begin{array}{c}0.078 \\
(0.019)^{* * *}\end{array}$ & $\begin{array}{c}0.058 \\
(0.019)^{* * *}\end{array}$ & $\begin{array}{c}0.034 \\
(0.017)^{* *}\end{array}$ \\
\hline \multicolumn{5}{|l|}{ Country samples } \\
\hline Peru & 640 & $\begin{array}{c}0.06 \\
(0.046)\end{array}$ & $\begin{array}{l}0.045 \\
(0.066)\end{array}$ & $\begin{array}{c}0.097 \\
(0.042)^{* *}\end{array}$ \\
\hline India & 859 & $\begin{array}{l}0.037 \\
(0.044)\end{array}$ & $\begin{array}{l}0.041 \\
(0.025)\end{array}$ & $\begin{array}{l}0.027 \\
(0.029)\end{array}$ \\
\hline Vietnam & 936 & $\begin{array}{c}0.067 \\
(0.027)^{* *}\end{array}$ & $\begin{array}{l}0.091 \\
(0.038)^{* *}\end{array}$ & $\begin{array}{l}0.029 \\
(0.037)\end{array}$ \\
\hline Ethiopia & 855 & $\begin{array}{l}0.117 \\
(0.038)^{* * *}\end{array}$ & $\begin{array}{l}0.043 \\
(0.036)\end{array}$ & $\begin{array}{l}0.012 \\
(0.037)\end{array}$ \\
\hline \multicolumn{5}{|l|}{ Pooled sample } \\
\hline Height-for-age $<-1$ & 2176 & $\begin{array}{c}0.081 \\
(0.038)^{* *}\end{array}$ & $\begin{array}{l}0.070 \\
(0.030)^{* *}\end{array}$ & $\begin{array}{l}0.053 \\
(0.029)^{*}\end{array}$ \\
\hline Height-for-age $\geqq-1$ & 1114 & $\begin{array}{l}0.047 \\
(0.048)\end{array}$ & $\begin{array}{l}0.042 \\
(0.061)\end{array}$ & $\begin{array}{l}0.060 \\
(0.048)\end{array}$ \\
\hline \multicolumn{5}{|l|}{ F-test eq. of coeff. } \\
\hline \multicolumn{5}{|l|}{ Baseline specification } \\
\hline $\mathrm{F}$ & & 2.64 & 0.70 & 0.59 \\
\hline p-value & & 0.055 & 0.557 & 0.624 \\
\hline \multicolumn{5}{|l|}{ Extended specification } \\
\hline $\mathrm{F}$ & & 1.98 & 0.81 & 0.85 \\
\hline p-value & & 0.123 & 0.494 & 0.471 \\
\hline
\end{tabular}

Variables are standardized to have mean 0 and variance 1 . Robust standard errors, clustered at the community level; ${ }^{*},{ }^{* *},{ }^{* *}$ denote significance at $10 \%, 5 \%$ and $1 \%$ levels. The baseline specification includes child and household level controls and community fixed effects. See the full list of variables in Section 3. The extended specification adds the following control variables: log household consumption expenditure (per capita), contemporaneous child body mass index, caregiver psychosocial competencies and whether the household was affected by different shocks when the child was aged 7 to 8 years or younger. 
Table A.5: OLS pooled sample, detailed: non-cognitive skills at age 11 to 12 and heightfor-age at age 7 to 8

\begin{tabular}{lccc} 
& $\begin{array}{c}\text { School } \\
\text { aspirations }\end{array}$ & $\begin{array}{c}\text { Self } \\
\text { efficacy }\end{array}$ & $\begin{array}{c}\text { Self } \\
\text { esteem }\end{array}$ \\
\cline { 2 - 4 } & $(1)$ & $(2)$ & $(3)$ \\
\hline PANEL A: Baseline specification, & pooled sample, & selected controls \\
Height for age z-score, age 7-8 & 0.104 & 0.064 & 0.051 \\
& $(0.018)^{* * *}$ & $(0.018)^{* * *}$ & $(0.018)^{* * *}$ \\
Caregiver's years of schooling & 0.089 & 0.043 & 0.132 \\
& $(0.023)^{* * *}$ & $(0.021)^{* *}$ & $(0.022)^{* * *}$ \\
Access to services & 0.097 & 0.063 & 0.102 \\
& $(0.027)^{* * *}$ & $(0.03)^{* *}$ & $(0.026)^{* * *}$
\end{tabular}

PANEL B: Extended specification, pooled sample, selected controls

$\begin{array}{llll}\text { Height for age z-score, age 7-8 } & 0.078 & 0.058 & 0.034\end{array}$

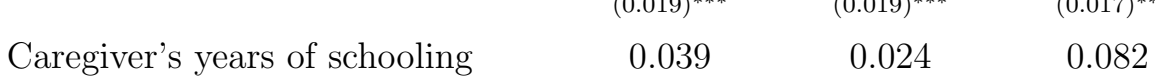

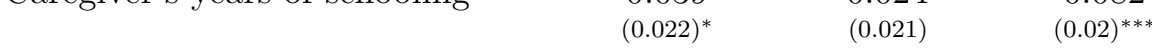

$\begin{array}{llll}\text { Access to services } & 0.049 & 0.039 & 0.07\end{array}$

$\begin{array}{lccc} & (0.027)^{*} & (0.03) & (0.026)^{* * *} \\ \text { Log-consumption per capita } & 0.073 & 0.048 & 0.07\end{array}$

$\begin{array}{ccc}0.02)^{* * *} & (0.02)^{* *} & (0.019)^{* * *}\end{array}$

Caregiver's aspirations for child $\quad 0.385$

$(0.032)^{* * *}$

Caregiver's self-efficacy $\quad 0.107$

$(0.026)^{* * *}$

$\begin{array}{ll}\text { Caregiver's self-esteem } & 0.272\end{array}$

$(0.025)^{* * *}$

\begin{tabular}{llll}
\hline $\mathrm{n}$ & 3290 & 3290 & 3290 \\
\hline \hline
\end{tabular}

Variables are standardized to have mean 0 and variance 1. Robust standard errors, clustered at the community level; ${ }^{*},{ }^{* *},{ }^{* * *}$ denote significance at $10 \%, 5 \%$ and $1 \%$ levels. The baseline specification includes child and household level controls and community fixed effects. See the full list of variables in Section 3. The extended specification adds the following control variables: log household consumption expenditure (per capita), contemporaneous child body mass index, caregiver psychosocial competencies and whether the household was affected by different shocks when the child was aged 7 to 8 years or younger. 
Table A.6: OLS pooled sample: The role of relative height

\begin{tabular}{ccc}
$\begin{array}{c}\text { School } \\
\text { aspirations }\end{array}$ & $\begin{array}{c}\text { Self } \\
\text { efficacy }\end{array}$ & $\begin{array}{c}\text { Self } \\
\text { esteem }\end{array}$ \\
\hline
\end{tabular}

\begin{tabular}{lccc}
\cline { 3 - 4 } & $(1)$ & $(2)$ & $(3)$ \\
\hline PANEL A: Extended specification, & communities & where $\%$ of & \\
stunted children is above 25 & & & \\
Height-for-age z-score, age 7-8 & 0.074 & 0.06 & 0.05 \\
& $(0.025)^{* * *}$ & $(0.026)^{* *}$ & $(0.025)^{* *}$ \\
$\mathrm{n}$ & 1768 & 1768 & 1768
\end{tabular}

PANEL B: Extended specification, communities where \% of stunted children is above 10

Height-for-age z-score, age 7-8

$\mathrm{n}$

$\begin{array}{ccc}0.084 & 0.061 & 0.042 \\ (0.02)^{* * *} & (0.02)^{* * *} & (0.017)^{* *} \\ 3051 & 3051 & 3051\end{array}$

Variables are standardized to have mean 0 and variance 1. Robust standard errors, clustered at the community level; ${ }^{*},{ }^{* *},{ }^{* * *}$ denote significance at $10 \%, 5 \%$ and $1 \%$ levels. 
Table A.7: OLS pooled sample, detailed: non-cognitive skills at age 11 to 12, schooling achievement at age 7 to 8 and height-for-age at age 7 to 8

\begin{tabular}{cccc} 
& $\begin{array}{c}\text { School } \\
\text { aspirations }\end{array}$ & $\begin{array}{c}\text { Self } \\
\text { efficacy }\end{array}$ & $\begin{array}{c}\text { Self } \\
\text { esteem }\end{array}$ \\
\cline { 2 - 4 } & $(1)$ & $(2)$ & $(3)$ \\
\hline PANEL A: Extended specification, pooled sample & & \\
Height for age z-score, age 7-8 & 0.083 & 0.054 & 0.031 \\
$(0.019)^{* * *}$ & $(0.02)^{* * *}$ & $(0.017)^{*}$
\end{tabular}

PANEL B: Extended specification, pooled sample, controlling

for schooling achievement

$\begin{array}{llll}\text { Height for age z-score, age 7-8 } & 0.071 & 0.047 & 0.021\end{array}$

$(0.054)^{* * *} \quad(0.05)^{* *} \quad(0.057)^{* *}$

$\begin{array}{llll}\text { High writing skills, age 7-8 } & 0.096 & 0.07 & 0.092\end{array}$

$\begin{array}{lccc} & (0.037)^{* * *} & (0.038)^{*} & (0.04)^{* *} \\ \text { Child started school at the norm-age } & 0.08 & 0.024 & 0.065 \\ & (0.058) & (0.058) & (0.06)\end{array}$

\begin{tabular}{llll}
\hline $\mathrm{n}$ & 3206 & 3206 & 3206 \\
\hline \hline
\end{tabular}

Variables are standardized to have mean 0 and variance 1. Robust standard errors, clustered at the community level; ${ }^{*},{ }^{* *},{ }^{* *}$ denote significance at $10 \%, 5 \%$ and $1 \%$ levels. 